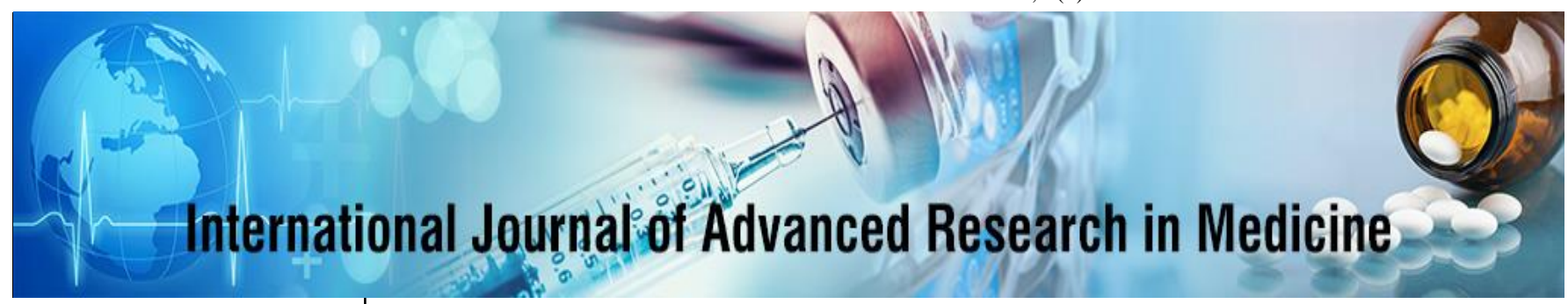

E-ISSN: 2706-9575

P-ISSN: 2706-9567

IJARM 2020; 2(2): 91-97

www.medicinepaper.net

Received: 08-05-2020

Accepted: 10-06-2020

Dr. Shaymaa SN Mehdi

Al Karkh Maternity Hospital

(Cabhs. OG.), Baghdad, Iraq

Dr. Alaa F Ibrahem

AlYarmouk Teaching Hospital

(Cabhs. MD), Baghdad, Iraq

Dr. Maha R Darweesh

Al Karkh Maternity Hospital

(Cabhs. OG.), Baghdad, Iraq
Corresponding Author: Dr. Shaymaa SN Mehdi Al Karkh Maternity Hospital (Cabhs. OG.), Baghdad, Iraq

\section{Finding the real effect of cesarean section in the second stage}

\author{
Dr. Shaymaa SN Mehdi, Dr. Alaa F Ibrahem and Dr. Maha R Darweesh
}

DOI: https://doi.org/10.22271/27069567.2020.v2.i2b.52

\begin{abstract}
Objective: Finding the real effect of cesarean section in the second stage of labour

Study Design: Observational prospective study.

Study Settings: Al Karkh Maternity Hospital/Baghdad/Iraq the period between April, 2018 and April, 2019.

Patients \& Method: A total of 333 term pregnant women in established labour and who had a primary emergency cesarean section either in the first stage or second stage of labor. Demographic characteristics were collected for all participants. A comparison of the outcomes of the two groups was done, it included a maternal outcome, composed of the following: intraoperative surgical complication, blood transfusion, endometritis, or wound complication and a neonatal outcome, which included the following: Apgar score at 5 minutes, weight, intubation in the absence of meconium, neonatal intensive care unit admission, fetal injury or neonatal death.

Results: Patients who had a cesarean delivery in the second stage of labour in our study were found to be older, multiparous and had a higher BMI at presentation. Teenagers were more likely to have cesarean section in first stage ( $12.5 \%$ vs. $3 \%$ in second stage). Second stage cesarean sections were associated with higher risk of uterine atony (RR 6.28 with 95\% CI 4.16-9.4), incisional extensions (RR 19.1 with $95 \%$ CI 8.9-40.9), accidental bladder injuries (RR 32.6 with 95\% CI 4.2-251), hematomas (RR 4.1 with 95\% CI 1.9-8.7), postoperative endometritis (RR 3.08 with 95\% CI 1.4-6.3), and required longer time to deliver the baby (5.1 vs. 3.8 minutes $p$ value 0.0001$)$. They were associated with delivery of higher birth weight infants (mean $3.63 \mathrm{~kg}$ vs. $3.1 \mathrm{~kg} \mathrm{p}$ value 0.0001 ). No difference found regarding the 5 minutes APGAR score, fetal injury, nor infant INCU admission between the two groups.

Conclusion: Cesarean delivery in the second stage of labour carries high risk of complications in our settings, both intra-operative surgical complications and short-term wound complications were higher than for cesarean delivery in the first stage of labour, and significant enough to warrant seeking for a proper intervention.
\end{abstract}

Keywords: Finding the real effect observational prospective study cesarean section

\section{Introduction}

Cesarean section is an operation that is performed to deliver the fetus through an abdominal and uterine incision. Legends and myths about the abdominal delivery of an infant appears in many cultures. The Roman law Lex Regis, which dates from $600 \mathrm{BC}$, required the infant to be delivered abdominally after maternal death to facilitate separate burial ${ }^{[1]}$.

The RCOG cited four usual indications, these are mainly: fetal compromise, "failure to progress" in labour, repeat CS and breech. The current most common reason given for performing a CS has changed and is now reported to be "maternal request" ${ }^{[2]}$. The escalating rates of cesareans are worrying, and the risk it poses on the overall health of the women is alarming, additionally an emergency cesarean section in the course of labour is related to poor maternal satisfaction and bonding with her newborn ${ }^{[3]}$. Labour, is defined as the function of the female organism by which the product of conception is expelled from the uterus through the vagina to the outside world.

There are four stages of labour, the first starts from the onset of labour to complete cervical dilatation. The second stage follows till delivery of the baby, then starts the third stage to the delivery of the placenta. The fourth stage describes the period of gaining uterine tone and patient's stabilization usually till about six hours postpartum ${ }^{[4]}$. In the keys to management of labor, the diagnosis of its onset is critical though often difficult. 
Active labour is defined as cervical dilatation of $4 \mathrm{~cm}$ effected by regular, painful uterine contractions ${ }^{[5]}$.

According the RCOG audit figures, about quarter of all cesareans performed for failed progress occurred at full dilatation. In many of the cases, no one attempted an instrumental birth vaginal (forceps or ventouse). In those where instrumental delivery was attempted, the audit noticed $35 \%$ failed rate for ventouse and $2 \%$ for forceps ${ }^{[6]}$.

Maternal and infant outcomes are to be affected by the timing of cesarean delivery, that is:

Second stage cesareans

1. Are more difficult technically due to engagement of the fetal head predisposing the mother to surgical injuries.

2. The delay of cesarean delivery until the second stage of labor may put the fetus at risk for morbidity due to hypoxia ${ }^{[7]}$.

Although the morbidity of cesarean in the second stage of labor has been described by many studies, these tend to focus on a comparison with instrumental vaginal delivery, while the morbidity in comparison with cesarean delivery in the first stage of labour is less well known.

In an attempt to understand the effect of a deeply impacted head in labour on the safety of cesarean section for the mother and her child, we decided to study the incidence of complications arising when dealing with cesarean section in the second stage of labour compared to cesarean in the first stage of labour.

\section{Material and Method}

This study represents a prospective observational study, carried at Al Karkh Maternity Hospital, a hospital that offers services to residents a vast region of Baghdad at the west bank of Tigris river.

Our sample consisted of 333 pregnant women carrying a term pregnancy with fetus in cephalic presentation, admitted to the hospital labour ward then underwent a primary emergency cesarean section either in the first stage or in the second stage of labour for indications we classified as fetal distress, failure of progress, or others during the period between April, 2018 and April, 2019.

The decision for cesarean was made by the senior specialist obstetrician on call that day.

We excluded cases where trials of instrumental vaginal deliveries were attempted, in order to eliminate those complications related to the use of forceps or ventouse from our study, and reduce confounders.

We compared the outcome of primary cesarean done in the first stage of labour to that of cesarean performed in the second stage in relation of maternal and neonatal short-term morbidity.

Also, we compared between the two groups in term of maternal characteristics, medical illnesses, the presence of chorioamnionitis, induction of labour, oxytocin use, the intraoperative time, days of hospital stay as well as the overall maternal satisfaction.

\section{Items collected}

- Mother's age

- Mother's BMI (calculated as weight in kilograms/height in meters $^{2}$ ) at time of presentation

- Parity

- Presence of medical problems like diabetes and hypertension

- Cervical dilatation through per Vaginum examination at presentation
- Chorioamnionitis, a clinical diagnosis based on criteria such as maternal fever, uterine tenderness, malodorous amniotic fluid, maternal or fetal tachycardia and maternal leukocytosis ${ }^{[41]}$.

- Use of induction of labour

- Oxytocin use

- Time between presentation and cesarean section

- Surgery duration and hospital stay duration

- Operative time was the time from skin incision to skin closure.

- Maternal intraoperative complications: uterine atony, accidental uterine incision extensions and lacerations, haematomas formation, bladder injury, bowel injuries, internal iliac artery ligation.

\section{Postoperative early complications}

1. Endometritis is clinically suggested by presence of abdominal pain, vaginal discharge, cervical tenderness, pyrexia, elevations in the peripheral white blood count and erythrocyte sedimentation rate ${ }^{[42]}$.

2. Wound complications; wound infection, hematoma, seroma, or separation. Many studies also reported "wound disruption," a combination of these outcomes which implies the need for further wound care ${ }^{[43]}$. Follow up through first two postoperative weeks was done on reviewing the patients at the day of stitches removal as well as through phone calls contact done at the sixth week postpartum.

3. Blood transfusion as an estimate for intraoperative blood loss.

\section{We excluded cases of transfusion for preoperative loss} i.e. APH.

- Satisfaction of the mothers was assessed through asking about satisfaction with outcome in general, if they felt they were cared for, as well as agreement with the decision of cesarean delivery.

- APGAR score (a modification of the original by Dr. Virginia Apgar in 1952, who devised a scoring system that was a rapid method of assessing the clinical status of the newborn infant at 1 minute of age and the need for prompt intervention to establish breathing). It comprises 5 components: heart rate, respiratory effort, muscle tone, reflex irritability, and color, each of which is given a score of 0,1 , or 2 . The score is reported at 1 and 5 minutes after birth ${ }^{[44]}$.

- Neonatal birth weight measured for all by same neonates weighing scale.

- Neonatal problems as need for intubation, injury, admission to INCU for more than 24 hours, RDS, asphyxia, encephalopathy or neonatal death were assessed by a competent paediatrician.

Consent were taken verbally, as our study was an observation of progress and no assignments to any sort of treatment was involved.

Permission from legal hospital authorities was not required for the same reason, as no intervention was required.

\section{Statistical analysis}

Analysis of data was carried out using the available statistical package of SPSS-17 (Statistical Packages for Social Sciences- version 17). 
Statistical analysis involved descriptive statistics such as frequency, percentages, averages, ranges (minimummaximum values), and standard deviation for both the groups

Calculating the confidence intervals of relative risk by calculator IE4.

The significance of difference between the variables was estimated by using independent student-t-test for difference between two means or averages, while different percentages were tested using chi-square test $\left(\chi^{2}\right.$-test $)$. Statistical significance was considered whenever the $\mathrm{P}$ value was less than 0.05 .

Further follow up and prompt management of maternal and neonatal complications was done by the assigned obstetrician and pediatrician respectively.

\section{Results}

This study involved 255 first stage cesarean sections and 78 cesareans performed in the second stage of labour.

Majority of patients were aged 20-24 years old, but second stage cesarean section tends to include older aged women as $33.3 \%$ were aged 30 years and more, compared to only $23.8 \%$ of first stage cesarean sections, while teenagers tend to be having cesareans in the first stage of labour $(12.5 \%$ vs.3.8\%), (p value 0.034). Table 1 .

Figure (1) more visibly shows the elevated frequency of patients aged 20-24 years old having a cesarean section, as well as higher occurrence of second stage cesarean in those aged 30-34 years.

As shown in table (2) and figure (2), the larger proportion of cesareans were done to nulliparous women, who had more often a cesarean during the first stage (62\%), while $43.6 \%$ of cesareans done in second stage of labour were done to nulliparous women. Whereas a parity of 2 and more was more encountered in the second stage cesarean sections ( $46.1 \%$ versus $22.7 \%$ ).

We classified women into either having BMI of less than 30 $\mathrm{kg} / \mathrm{m}^{2}$ or equal and higher than $30 \mathrm{~kg} / \mathrm{m}^{2}$.

The portion of women with BMI of 30 and more formed $70.2 \%$ of first and $53.8 \%$ of second stage cesareans, we found higher second stage cesareans with a BMI of less than $30 \mathrm{~kg} / \mathrm{m}^{2}, 46.2 \%$ versus $29.8 \%$ with first stage as shown in table 3 .

We found that the main indications for primary cesarean section in the absence of malpresentation were failed progress in labour, accounting for $74.4 \%$ of second stage cesareans, and $36.9 \%$ of first stage cesarean sections, Fetal distress was much less often encountered as an indication for cesareans in the second stage $(24.4 \%)$, but still comprised $31 \%$ of 8.8 jo in first stage of labour $(32.1 \%$ ), these were not found in second stage except for one case of maternal distress as shown in table 4.

No significant difference in term of time from presentation till cesarean section was done, presentation with chorioamnionitis, or days of hospital stay between the two groups. Oxytocin use and duration was more in the second stage cesarean section. Concerning cervical dilatation at presentation, more advanced labors were associated with second stage cesarean sections with mean of $6 \mathrm{~cm}$ dilatation. Total cesarean time (36.9 minutes) and time from skin incision till delivery of baby (5.1 minutes) were longer in second stage cesareans, more clarified by figure (3) and table (5).

Induction of labour was more associated with cesareans in the second stage $(20.5 \%)$ than first stage $(5.5 \%)$.
Significantly increased intraoperative complications, including uterine atony $(61.5 \%$ versus $9.8 \%)$, incision extension $(52.6 \%$ versus $2.7 \%$ ), bladder injuries $(12.8 \%$ versus $0.4 \%$ ), blood transfusions (3.8\% versus $0.8 \%)$, were encountered in cesareans done in the second stage of labour as described by table 5 .

Calculated risks were for uterine atony (RR 6.28, 95\% CI 4.1-9.4), incisional extensions (RR 19.1 95\% CI 8.9-40.9), accidental bladder injuries (RR $32.695 \% \mathrm{CI} 4.2-251$ ), and hematomas (RR $4.195 \%$ CI 1.9-8.7). (Figure 4) and (Table 6).

Endometritis occurred in $15.4 \%$ of cesareans done in second stage versus $5.1 \%$ of cesareans done in the first stage (RR 3.08 with 95\% CI 1.4-6.5). Wound complications were more in second stage cesareans $(17.5 \%$ vs. $8.1 \%$ p value $0.054)$, but wasn't statistically significant as RR was $(2.18$ at $95 \%$ CI 0.8-5.6).

Only 98 of patients done cesarean in first stage and 40 in the second stage did contact us postpartum for wound examination.

Maternal overall satisfaction was better when cesarean was performed in the first stage $(84.3 \%)$, and $50 \%$ of patients only were satisfied when delayed till second stage (table 6), (Figure 4).

The stage of labour at which cesarean section was done did not affect the neonatal outcome in general and as shown in table (7), but the mean neonatal weight was $3.6 \mathrm{~kg} \pm 0.56$ for cesareans done in second stage and was significantly higher than the mean birth weight of neonates born as a product of cesarean done in first stage of labour.

\section{Discussion}

This study compared maternal characteristics, adverse maternal outcome as well as neonatal outcome in both first and second stage of labour.

When cesarean section was performed in second stage, patients tend to be older $(33.3 \%$ were $>30$ years versus $23 \%$ ) and were less likely to be teenagers (3.8\% vs. $12.5 \%$ in first stage $).(p=.034)$

This result is consistent with a study by Moodley J. et al. ${ }^{[8]}$ (mean age 23.7 vs. 20.2 years p value < 0.001) and Isha et al., mean age 25.2 years, and $70 \%$ had BMI (25-30) versus $47 \%$ in our study ${ }^{[9]}$.

Isha et al. suggested as well, that nulliparity was more often encountered in the second stage, we found contradictory results, most of our patients in the second stage group had parities, and although the difference was of high significance ( $\mathrm{p}$ value 0.001 ), we could not suggest a sound explanation for this finding ${ }^{[9]}$.

More advanced cervical dilatation at presentation in patients of the second stage cesarean section group $(6 \mathrm{~cm}$ vs. $3 \mathrm{~cm}, \mathrm{p}$ value 0.0001 ), is likely to be due to delayed admission as the hospital receives all kinds of referrals, the delay could be due to lack of transport, money, non-formal and delayed decision by the referring side.

There was a tendency to longer oxytocin use (4.6 vs. 3.6 hours $\mathrm{p}$ value 0.001 ) in second stage group, also cesarean deliveries in this group were more often preceded by induction of labour (20.5\% vs. $5.5 \%$ p value 0.0001$)$, perhaps explained by poor selection criteria for induction. More importantly, cesarean sections done in the second stage of labour was significantly associated with longer time from incision to delivery (3.8 vs. 5.1 minutes $\mathrm{p}$ value 0.0001 ), and longer total operative time (31.2 vs. 36.9 
minutes p value 0.0001), which is consistent with the studies by Alexander et al. ${ }^{[10]}$, Moodley et al. ${ }^{[8]}$ (35 vs. $30 \mathrm{~min} \mathrm{p}$ value 0.02$)^{[8]}$ and Cebekulu et al. (45 vs. $30 \mathrm{~min} \mathrm{p}$ value < $0.001)^{[11]}$.

We also agree to the Alexander study in that cesarean sections done in the second stage of labour were more likely to be associated with intraoperative complications like uterine atony $(61.5 \%$ vs. $9.8 \%$ p value 0.0001$)$, incisional extensions $(52.6 \%$ vs. $2.7 \%$ p value 0.054$)$, accidental bladder injuries (12.8 vs. $0.4 \%$ p value 0.0001$)$, hematomas ( $17.9 \%$ vs. $4.3 \%$ p value 0.0001$)$.

These findings reflect the difficulties encountered in delivering an impacted head of the large baby within a disproportionate pelvis, and the lack of an agreed technique to deliver the impacted head as many studies has proposed the push from below, the pull as in extraction of breech may be more safe as suggested by Levi et al. ${ }^{[13]}$.

Further more Singh et al. cited that the National Sentinel Caesarean Section Audit Report, published by the Royal College of Obstetricians and Gynecologists recommends a consultant presence when caesarean section is performed at full dilatation, and proposed the use of the disimpaction system (Fetal Disimpacting System $®$ ) which he found safer than pushing by an assistant, yet this is still not being adopted ${ }^{[14]}$.

Regarding the postoperative period, as mentioned previously we observed the females through a short period, as most stayed for 2 or 3 days and did discharged on the family responsibility, but we have noticed higher postoperative pyrexia suggesting endometritis in the group of second stage of labour ( $15.1 \%$ vs. $5.4 \%$ p value 0.002$)$. We contacting the women at removal of the stitches and at 4-6 weeks from delivery through available phone calls, we found as many as 7 of 40 patients of the second stage group developed a wound complication $(17.5 \%$ vs. $8.1 \%$ p value 0.054). This was of no statistical difference and was similar to the results of Alexander et al. ${ }^{[10]}$ and Renate et al. ${ }^{[15]}$.

Less maternal satisfaction found to be associated with cesarean section in the second stage of labour $(50 \%$ vs. $84.3 \% \mathrm{p}$ value 0.0001), and could be explained by the longer journey, as well as being a result of poor communication and a lack of trust between doctors and patients, realizing that communication and trust may be difficult to establish when meeting a patient for the first time.

The neonatal composite was not much affected in our results by the stage of labour at which cesarean section was performed, but the infants were larger in the second stage group, consistent with the findings of Alexander et al. ${ }^{[10]}$ and Davis et al. ${ }^{[16]}$ which showed that neonatal outcome (low APGAR, NICU admissions) were concurrent in both groups.

\section{Conclusions}

Cesarean section in the second stage is still representing a challenge.

It is associated with high risk of maternal complications and should be addressed promptly by including training on safe techniques of second stage cesarean deliveries in the regular national training programs for obstetric emergencies.
Conflicts of Interest: The authors declare no conflict of interest.

\section{Tables}

Table 1: Age distribution by stage of labour at time of cesarean section ${ }^{[1]}$

\begin{tabular}{|c|c|c|c|c|c|}
\hline \multirow{2}{*}{ Mother age (years) } & \multicolumn{2}{|c|}{ First stage } & \multicolumn{2}{|c|}{ Second stage } & \multirow{2}{*}{ P value } \\
\hline & No & $\%$ & No & $\%$ & \\
\hline$<20$ & 32 & 12.5 & 3 & 3.8 & \\
\hline $20-24$ & 99 & 38.8 & 28 & 35.9 & \\
\hline $25-29$ & 63 & 24.7 & 21 & 26.9 & \\
\hline $30-34$ & 27 & 10.6 & 17 & 21.8 & $0.034 *$ \\
\hline$=>35$ & 34 & 13.3 & 9 & 11.5 & \\
\hline $\begin{array}{c}\text { Mean } \pm \text { SD } \\
\text { Min-Max }\end{array}$ & \multicolumn{2}{|c|}{$25.49 \pm 6.21$} & $26.74 \pm 5.67$ & $\begin{array}{l} \pm 5.67 \\
41\end{array}$ & \\
\hline
\end{tabular}

*Significant at 0.05 level of significance using Pearson chi-squared test.

Table 2: Parity distribution according the stage of labour at cesarean section ${ }^{[2]}$

\begin{tabular}{|c|c|c|c|c|c|}
\hline \multirow{2}{*}{ Parity } & \multicolumn{2}{|c|}{ First stage } & \multicolumn{2}{c|}{ Second stage } & \multirow{2}{*}{ P value } \\
\cline { 2 - 5 } & No & \% & No & \% & \\
\hline Para 0 & 158 & 62.0 & 34 & 43.6 & \\
\hline Para 1 & 39 & 15.3 & 8 & 10.3 & \\
\hline Para 2-3 & 35 & 13.7 & 18 & 23.1 & \multirow{2}{*}{$0.0001^{*}$} \\
\hline Para 4 and more & 23 & 9.0 & 18 & 23 & \\
\hline Mean \pm SD & \multicolumn{2}{|c|}{$0.99 \pm 1.76$} & \multicolumn{2}{|c|}{$1.95 \pm 2.38$} & \\
Min-Max & \multicolumn{2}{|c|}{$0-9$} & \multicolumn{2}{c|}{$0-8$} & \\
\hline
\end{tabular}

*Significant at 0.05 level of significance using Pearson chi-squared test.

Table 3: BMI at presentation distributed by stage of labor at cesarean section ${ }^{[3]}$

\begin{tabular}{|c|c|c|c|c|c|}
\hline BMI & \multicolumn{2}{|c|}{ First stage } & \multicolumn{2}{|c|}{ Second stage } & \multirow{2}{*}{$P$ value } \\
\hline $\mathrm{Kg} / \mathrm{m}^{2}$ & No & $\%$ & No & $\%$ & \\
\hline$<30$ & 76 & 29.8 & 36 & 46.2 & \multirow{3}{*}{$0.007 *$} \\
\hline$>=30$ & 179 & 70.2 & 42 & 53.8 & \\
\hline & \multicolumn{2}{|c|}{$\begin{array}{c}31.44 \pm 3.00 \\
26-40\end{array}$} & \multicolumn{2}{|c|}{$\begin{array}{c}30.44 \pm 3.27 \\
26-38\end{array}$} & \\
\hline
\end{tabular}

*Significant at 0.05 level of significance using Pearson chi-squared test.

Table 4: Description of various indications for emergency cesarean section in our study ${ }^{[4]}$

\begin{tabular}{|c|c|c|c|c|c|}
\hline \multirow{2}{*}{ Indication for Caesarean } & \multicolumn{2}{|c|}{ First stage } & \multicolumn{2}{|c|}{ Second stage } & \multirow{2}{*}{ P value } \\
\cline { 2 - 5 } & No & \% & No & \% & \\
\hline Fetal distress & 79 & 31.0 & 19 & 24.4 & \\
\hline Failure of progress & 94 & 36.9 & 58 & 74.4 \\
\hline Abruption & 13 & 5.1 & - & - \\
\hline Cephalopelvic disproportion & 8 & 3.1 & - & - \\
\hline Chorioamnionitis & 8 & 3.1 & - & - \\
\hline Maternal distress & 1 & 0.4 & 1 & 1.3 \\
\hline Meconium & 25 & 9.8 & - & - \\
\hline Oligohydramnios & 4 & 1.6 & - & - \\
\hline Polyhydramnios & 1 & 0.4 & - & - \\
\hline Preeclampsia & 20 & 7.8 & - & - \\
\hline Prolonged rupture of membrane & 2 & 0.8 & - & - & \\
\hline
\end{tabular}


Table 5: Obstetric Characteristics distributed by stage of labour at cesarean section ${ }^{[5]}$

\begin{tabular}{|c|c|c|c|c|c|}
\hline \multirow{2}{*}{ Parameter } & \multicolumn{2}{|c|}{ First stage } & \multicolumn{2}{|c|}{ Second stage } & \multirow{2}{*}{ P value } \\
\cline { 2 - 5 } & No & $\begin{array}{c}\text { Mean } \pm \text { SD } \\
\text { Min-Max }\end{array}$ & No & $\begin{array}{c}\text { Mean } \pm \text { SD } \\
\text { Min-Max }\end{array}$ & \\
\hline Cervical dilatation (cm)at presentation & 255 & $3.25 \pm 3.18,1-43$ & 78 & $6.01 \pm 2.30,1-10$ & $0.0001^{*}$ \\
\hline Time from presentation till cesarean (hrs) & 255 & $4.31 \pm 3.39,1-24$ & 78 & $4.76 \pm 2.01,1-10$ & 0.269 \\
\hline Oxytocin use (hrs) & 89 & $3.63 \pm 1.45,1-8$ & 40 & $4.63 \pm 1.55,2-8$ & $0.001^{*}$ \\
\hline Chorioamnionitis (hrs) & 10 & $1.60 \pm 0.84,1-3$ & 3 & $2.67 \pm 1.15,2-4$ & 0.102 \\
\hline Time from incision to delivery(minutes) & 255 & $3.88 \pm 0.90,2-6$ & 78 & $5.10 \pm 0.91,3-7$ & $0.0001^{*}$ \\
\hline Total Caesarean time(minutes) & 255 & $31.23 \pm 5.67,4-40$ & 78 & $36.97 \pm 5.54,25-48$ & $0.0001^{*}$ \\
\hline Days of hospital stays & 253 & $2.53 \pm 1.81,1-29$ & 78 & $2.77 \pm 0.66,2-5$ & 0.254 \\
\hline Induction of labour No & No. & $\mathbf{\%}$ & No. & \% & P value \\
\hline Yes & 241 & 94.5 & 62 & 79.5 & \multirow{2}{*}{$0.0001^{* *}$} \\
\hline
\end{tabular}

*Significant at 0.05 level of significance using t-test for two independent means.

** Significant at 0.05 level of significance using Pearson chi-squared test.

Table 6: Maternal outcome distributed by stage of labour at time of cesarean section ${ }^{[6]}$

\begin{tabular}{|c|c|c|c|c|c|}
\hline \multirow{2}{*}{ Maternal complications } & \multicolumn{2}{|c|}{ First stage $(n=255)$} & \multicolumn{2}{|c|}{ Second stage $(n=78)$} & \multirow{2}{*}{$P$ value } \\
\hline & No & $\%$ & No & $\%$ & \\
\hline Uterine atony No & 230 & 90.2 & 30 & 38.5 & \multirow{2}{*}{$0.0001 *$} \\
\hline Yes & 25 & 9.8 & 48 & 61.5 & \\
\hline Uterine incision extension No & 248 & 97.3 & 37 & 47.4 & \multirow{2}{*}{$0.0001^{*}$} \\
\hline Yes & 7 & 2.7 & 41 & 52.6 & \\
\hline Hematoma No & 244 & 95.7 & 64 & 82.1 & \multirow{2}{*}{$0.0001 *$} \\
\hline Yes & 11 & 4.3 & 14 & 17.9 & \\
\hline Cystotomy or bowel injury No & 254 & 99.6 & 68 & 87.2 & \multirow{2}{*}{$0.0001 *$} \\
\hline Yes & 1 & 0.4 & 10 & 12.8 & \\
\hline Internal iliac artery ligation No & 255 & 100.0 & 77 & 98.7 & \multirow{2}{*}{-} \\
\hline Yes & - & - & 1 & 1.3 & \\
\hline Blood transfusion No & 253 & 99.2 & 75 & 96.2 & \multirow{2}{*}{0.052} \\
\hline Yes & 2 & 0.8 & 3 & 3.8 & \\
\hline Endometritis No & 242 & 94.9 & 66 & 84.6 & \multirow{2}{*}{$0.002 *$} \\
\hline Yes & 13 & 5.1 & 12 & 15.4 & \\
\hline Wound complications No & 90 & 91.9 & 33 & 82.5 & \multirow{2}{*}{$0.054 *$} \\
\hline Yes & 8 & 8.1 & 7 & 17.5 & \\
\hline Mother overall satisfaction No & 40 & 15.7 & 39 & 50.0 & \multirow{2}{*}{$0.0001 *$} \\
\hline Yes & 215 & 84.3 & 39 & 50.0 & \\
\hline
\end{tabular}

*Significant at 0.05 level of significance using Pearson chi-squared test.

Table 7: Neonatal characteristics and outcome according the stage of labour at cesarean section ${ }^{[7]}$

\begin{tabular}{|c|c|c|c|c|c|}
\hline \multirow{2}{*}{ Neonatal characteristics } & \multicolumn{2}{|c|}{ First stage $(\mathrm{n}=255)$} & \multicolumn{2}{|c|}{ Second stage $(n=78)$} & \multirow{2}{*}{$P$ value } \\
\hline & No & Mean \pm SD & No & Mean \pm SD & \\
\hline Neonatal weight & 255 & $3.15 \pm 0.54,1.6-5$ & 78 & $3.63 \pm 0.56,2.3-4.7$ & $0.0001 *$ \\
\hline Gestational age (weeks) & 255 & $38.16 \pm 2.12,36-42$ & 78 & $38.19 \pm 1.02,36-41$ & 0.886 \\
\hline \multirow[t]{2}{*}{ Apgar score (at 5 minutes) } & 255 & $8.33 \pm 1.21,3-10$ & 78 & $8.14 \pm 1.47,4-10$ & 0.263 \\
\hline & & Percentage $\%$ & & Percentage $\%$ & \\
\hline Intubation No & 250 & 98.0 & 76 & 97.4 & \multirow{2}{*}{$0.745 * *$} \\
\hline Yes & 5 & 2.0 & 2 & 2.6 & \\
\hline Fetal injury No & 243 & 95.3 & 76 & 97.4 & \multirow{3}{*}{$0.573 * *$} \\
\hline RDS & 3 & 1.2 & - & - & \\
\hline Yes & 9 & 3.5 & 2 & 2.6 & \\
\hline INCU admission more than 24 hours No & 219 & 85.9 & 71 & 91.0 & \multirow{2}{*}{$0.236 * *$} \\
\hline Yes & 36 & 14.1 & 7 & 9.0 & \\
\hline Neonatal death No & 255 & 100.0 & 77 & 98.7 & \multirow[b]{2}{*}{ - } \\
\hline Yes & - & - & 1 & 1.3 & \\
\hline
\end{tabular}

* Significant at 0.05 level of significance using t-test for two independent means

**Significant at 0.05 level of significance using Pearson chi-squared test. 


\section{Figures}

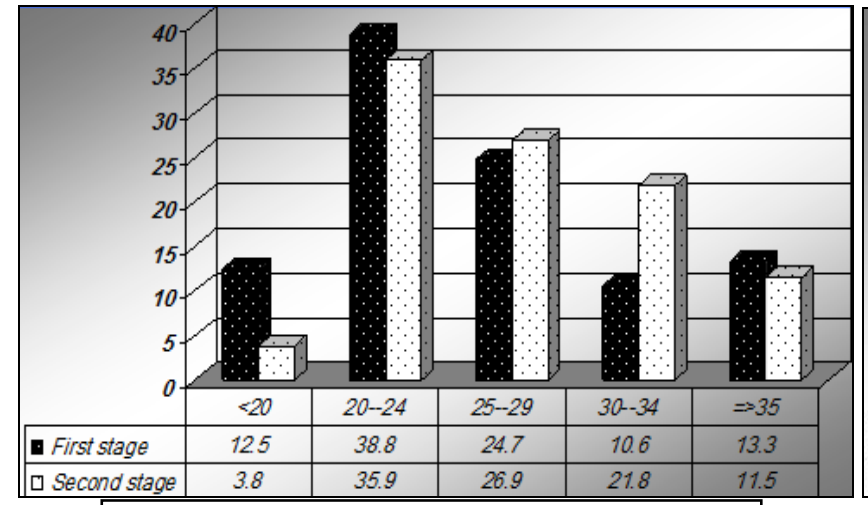

Fig 1: Age distribution of pregnant women by stage of labour at time of cesarean section ${ }^{[1]}$

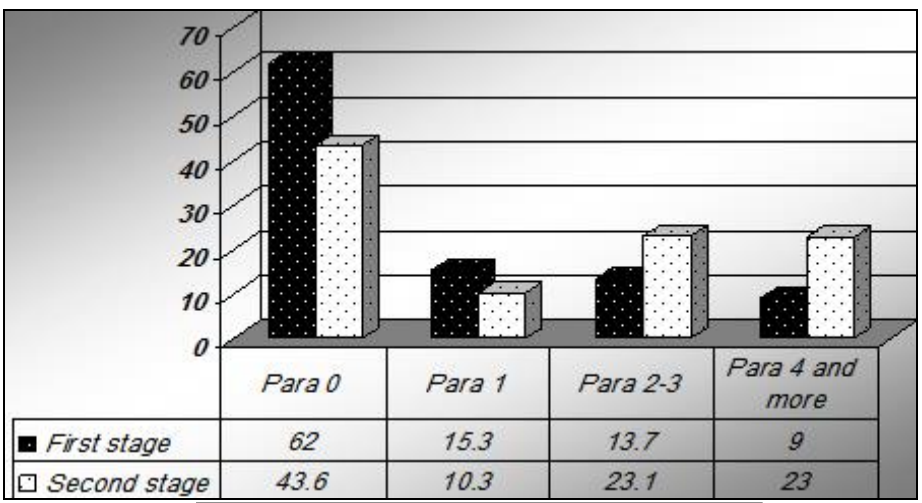

Fig 2: Parity distribution according to the stage of labour at cesarean section ${ }^{[2]}$

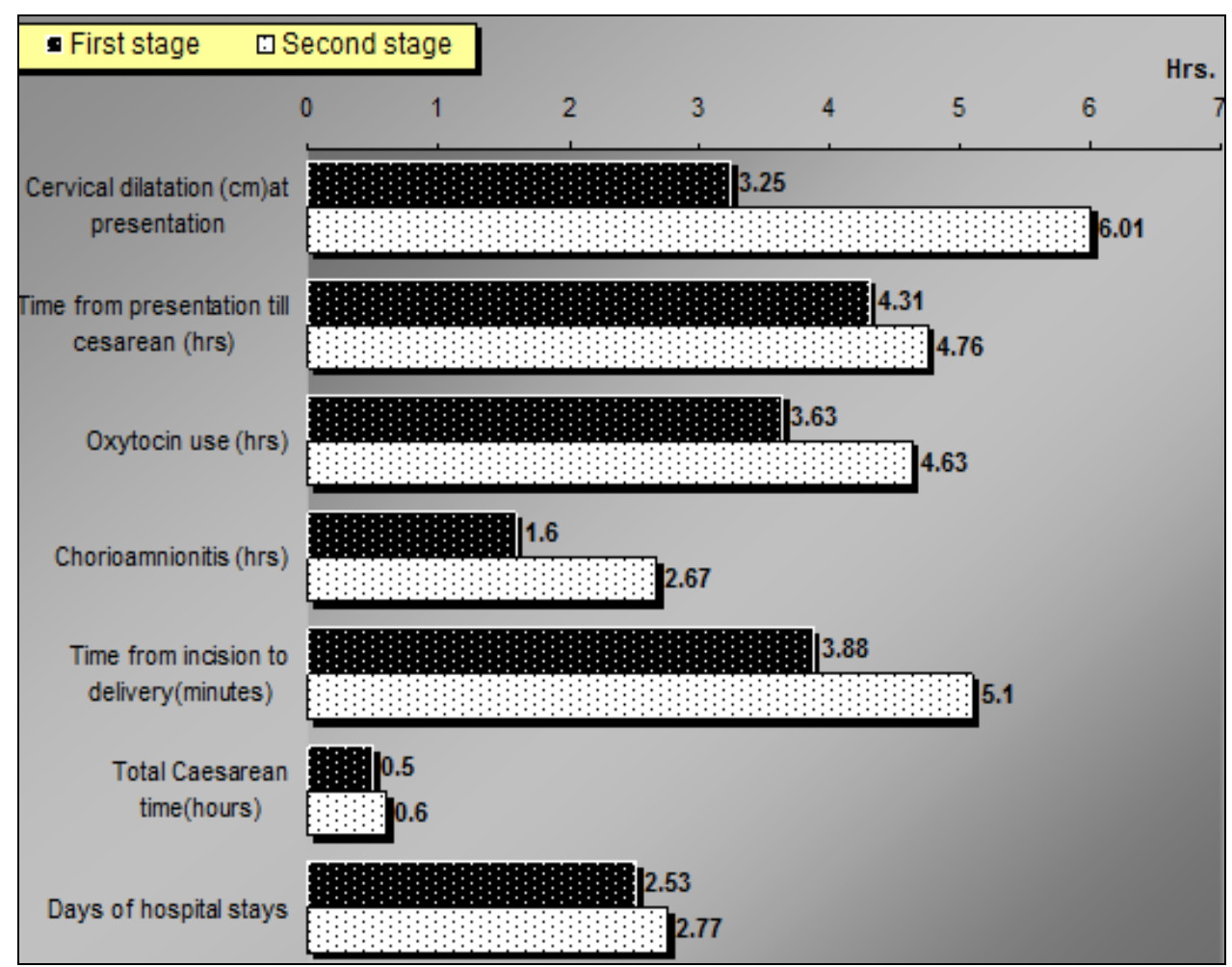

Fig 3: Obstetric Characteristics distributed by stage of labour at cesarean section ${ }^{[3]}$

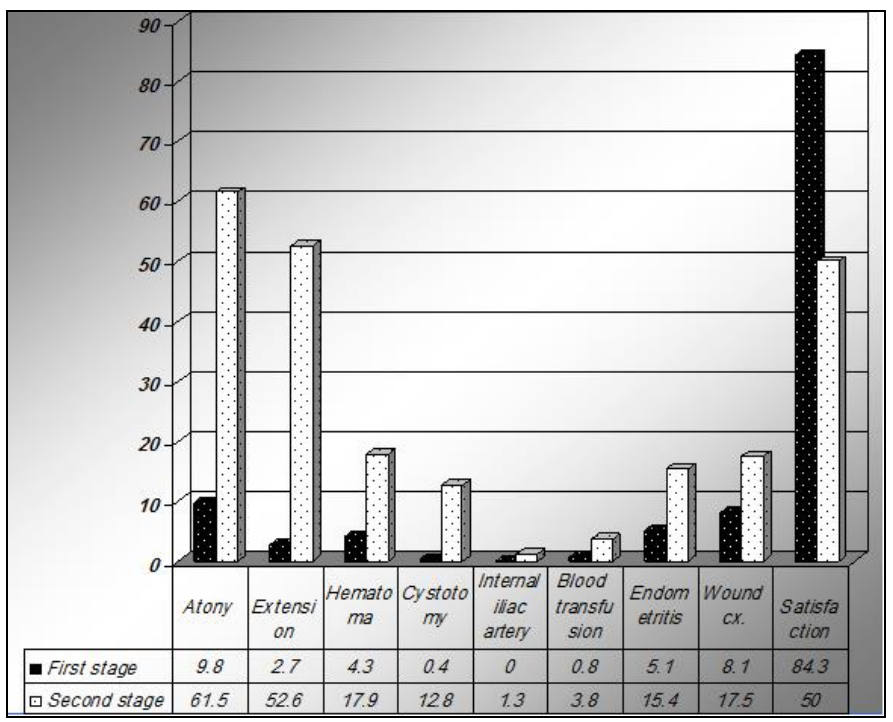

Fig 4: Maternal outcome distributed by stage of labour at time of cesarean section ${ }^{[4]}$ 


\section{References}

1. Lanneau G, Muffley P et al. Global Library of Women's Medicine. 2008; 10:38-43. (ISSN: 1756-2228)

2. Cesarean section: summary of updates NICE guidance. BMJ 2011; 343:D7-108.

3. Akuma Adugna. Predisposing factors for cesarean section. LAP LAMBERT Academic Publishing, 2019.

4. Calvein J. Anita Backus Chang. Normal labour, delivery, and postpartum care, Essentials of Obstetrics and Gynecology. Neville F. Hacker et al, W.B. Saunders Company. 4th edition, Chapter 9, 2004, 112-117.

5. Intrapartum care, for healthy women and babies. National Collaborating Centre for Women's and Children's Health. CG190. Updated, 2014, 2017.

6. James M Alexander, Kenneth J Leveno. Comparison of maternal and infant outcomes from primary cesarean delivery during the second compared with first stage of labor. Obstetrics and Gynecology. 2007; 109(4):917.

7. Gifford DS, Morton SC. Lack of progress in labor as a reason for cesarean. Obstetric and Gynecology. 2000; 95:589-95.

8. Moodley J, Devjee J, Khedun SM, Esterhuizen T. Second stage primary cesarean deliveries: are maternal complications increased. SA Fam Pract. 2009; 51(4):328-31.

9. Isha Prabhal AL, Vikram Dutta, Aayushi Kaushal. Demographic profile in women undergoing second stage cesarean section. International Journal of Reproduction, Contraception, Obstetrics and Gynecology. 2020; 9(2):570-574, 8:12.

10. Alexander James M, Kenneth J, Leveno Rouse, Dwight $\mathrm{J}$ et al. Comparison of maternal and infant outcomes from primary cesarean delivery during the second compared with first stage of labour. Am J Obstet Gynecol. 2007:109:917-21.

11. Cebekulu L, Buchmann EJ. Complications associated with cesarean section in the second stage of labor International Journal of Gynecology and Obstetrics. 2006; 95:110-114.

12. Jain N, Lal P. A Retrospective comparative study of fetomaternal outcome in the first and second stages of labour. Obstet. Gynaecol. Int. 201, 4.

13. Levy R, Chernomoretz T, Appelman Z, Levin DOrY, Hagay ZJ. Head pushing versus reverse breech extraction in cases of impacted fetal head during cesarean section. Eur J Obstet Gyn RB. 2005; 121(1):2426.

14. Singh M, Varma R. Reducing complications associated with a deeply engaged head at caesarean section: a simple instrument. The Obstetrician \& Gynecologist. 2008; 10:38-41.

15. Renate ME, Häger MD. Complications of cesarean deliveries: Rates and risk factors American Journal of Obstetrics and Gynecology. 2004; 190(2):428-434.

16. Davis G, Fleming T, Ford K, Mouawad MR, Ludlow J. Cesarean section at full cervical dilatation. Aust NZ J Obstet Gyn. 2015, 55(6):565-571. 